\title{
Identifying erlotinib-sensitive non-small cell lung carcinoma tumors in mice using $\left[{ }^{11} \mathrm{C}\right]$ erlotinib PET
}

\author{
Galith Abourbeh*, Batel Itamar, Olga Salnikov, Sergey Beltsov and Eyal Mishani
}

\begin{abstract}
Background: Non-small cell lung carcinoma (NSCLC) represents approximately $80 \%$ of lung cancer cases, and over $60 \%$ of these tumors express the epidermal growth factor receptor (EGFR). Activating mutations in the tyrosine kinase (TK) domain of the EGFR are detected in 10\% to 30\% of NSCLC patients, and evidence of their presence is a prerequisite for initiation of first-line therapy with selective TK inhibitors (TKIs), such as gefitinib and erlotinib. To date, the selection of candidate patients for first-line treatment with EGFR TKIs requires an invasive tumor biopsy to affirm the mutational status of the receptor. This study was designed to evaluate whether positron emission tomography (PET) of NSCLC tumor-bearing mice using $\left[{ }^{11} \mathrm{C}\right]$ erlotinib could distinguish erlotinib-sensitive from erlotinib-insensitive or erlotinib-resistant tumors.
\end{abstract}

Methods: Four human NSCLC cell lines were employed, expressing either of the following forms of the EGFR: (i) the wild-type receptor (QG56 cells), (ii) a mutant with an exon 19 in-frame deletion (HCC827 cells), (iii) a mutant with the exon 21 L858R point mutation (NCl-H3255 cells), and (iv) a double mutant harboring the L858R and T790M mutations (NCl-H1975 cells). Sensitivity of each cell line to the anti-proliferative effect of erlotinib was determined in vitro. In vivo PET imaging studies following i.v. injection of $\left[{ }^{11} \mathrm{C}\right]$ erlotinib were carried out in nude mice bearing subcutaneous (s.c.) xenografts of the four cell lines.

Results: Cells harboring activating mutations in the EGFR TK domain ( $\mathrm{HCC} 827$ and $\mathrm{NCl}-\mathrm{H} 3255)$ were approximately 1,000- and 100-fold more sensitive to erlotinib treatment in vitro, respectively, compared to the other two cell lines. $\left[{ }^{11} \mathrm{C}\right]$ Erlotinib PET scans could differentiate erlotinib-sensitive tumors from insensitive (QG56) or resistant (NCI-H1975) tumors already at 12 min after injection. Nonetheless, the uptake in HCC827 tumors was significantly higher than that in NCI-H3255, possibly reflecting differences in ATP and erlotinib affinities between the EGFR mutants.

Conclusions: $\left[{ }^{11} \mathrm{C}\right]$ Erlotinib imaging in mice differentiates erlotinib-sensitive NSCLC tumors from erlotinib-insensitive or erlotinib-resistant ones.

Keywords: $\left[{ }^{11}\right.$ C]Erlotinib; PET; Imaging; NSCLC; EGFR; TKI

\section{Background}

The mortality from lung cancer is high and accounts for almost $30 \%$ of cancer-related deaths. Though the overall death rate from lung cancer is declining, the prognosis of stage IV non-small cell lung carcinoma (NSCLC) patients is poor, with a 5 -year survival rate lower than $5 \%[1,2]$.

NSCLC represents approximately $80 \%$ of lung cancer cases, and over $60 \%$ of these tumors express the epidermal growth factor receptor (EGFR), rendering it a primary

* Correspondence: abourbehg@hadassah.org.il

Cyclotron-Radiochemistry-MicroPET Unit, Hadassah Hebrew University Hospital, Jerusalem 91120, Israel protein of interest of different targeted therapeutic approaches [1,3-5].

Alterations in the tyrosine kinase (TK) domain of the EGFR, such as the L858R point mutation and the E746A750 deletion mutation, occur in $10 \%$ to $15 \%$ of Caucasian and $30 \%$ to $50 \%$ of Asian NSCLC patients [6]. These mutations are associated with a distinct pattern of EGFR downstream signaling and confer 'oncogene addiction', i.e., dependence of cells upon EGFR activity. Thus, in the presence of these sensitizing mutations, inhibition of EGFR signaling is detrimental to the cells [7-9].

Low molecular weight TK inhibitors (TKIs) of the EGFR, such as gefitinib and erlotinib, have been proven 
particularly effective as first-line treatment in NSCLC patients, whose tumors harbor activating mutations in the EGFR TK domain. Specifically, in the presence of such mutations, treatment with a selective EGFR TKI is associated with superior progression-free survival (PFS), increased overall response rate (ORR), a more favorable toxicity profile, and an improved quality of life with respect to cytotoxic chemotherapy $[1,6,10,11]$. Moreover, first-line treatment of mutation-negative NSCLC patients using selective EGFR TKIs is harmful and worsens PFS. Accordingly, EGFR TKIs are recommended as first-line treatment only for patients whose tumors harbor activating EGFR TK mutations $[1,10]$.

Despite the significant improvement in PFS and ORR, all patients treated with EGFR TKIs inevitably develop resistance. Emergence of a secondary mutation in the TK domain of the receptor, such as the T790M point mutation, is the most common mechanism of resistance to EGFR TKIs, accounting for approximately $50 \%$ of patients, whose disease had progressed following treatment with TKIs $[1,6,12,13]$.

At present, identification of candidate NSCLC patients for first-line treatment with TKIs requires screening for the existence of mutations, using tumor genotyping techniques and/or immunohistochemistry (IHC) $[1,14]$. These approaches require invasive procedures for tissue biopsies, which are not always readily accessible for sampling, could be of insufficient quality, and require time for mutation analysis. Furthermore, owing to the heterogeneity of tumors vis-à-vis the mutational status of EGFR, the data obtained from tissue samples does not necessarily reflect that of the entire primary tumor and is of limited value in predicting the molecular characteristics of distant metastases.

These hurdles have urged the pursuit of alternative, non-invasive approaches for evaluating and quantifying the mutational status of EGFR $[15,16]$. The use of a noninvasive imaging technique, such as positron emission tomography (PET), for identifying the mutational status of the EGFR TK in tumors should facilitate patient stratification prior to initiation of treatment with TKIs. Moreover, since approximately $50 \%$ of NSCLC patients treated with TKIs ultimately develop secondary mutations in the EGFR TK domain in tumors and consequently resistance to erlotinib treatment, PET should also afford longitudinal monitoring of EGFR mutational status in tumors.

During the past decade, numerous radiolabeled EGFRtargeted agents, namely antibodies and TKIs, have been investigated as probes for visualizing and quantifying EGFR expression in tumors using nuclear imaging modalities, such as single photon emission computed tomography (SPECT) and PET [16-29]. Notably, both erlotinib and gefitinib have been labeled with positron-emitting isotopes and evaluated in preclinical animal models. Reports on ${ }^{11} \mathrm{C}$ - and ${ }^{18} \mathrm{~F}$-labeled gefitinib imaging in tumor-bearing mice indicated that $\left[{ }^{11} \mathrm{C}\right]$ gefitinib has more potential than its fluorine-18-labeled congener, although to date, neither has progressed into clinical trials [26,29]. Conversely, reports on $\left[{ }^{11} \mathrm{C}\right]$ erlotinib have revealed its added value in imaging EGFR mutant-positive tumors not only in mice $[19,24]$, but also in humans $[18,20,28]$. Hitherto, elevated tumor uptake of $\left[{ }^{11} \mathrm{C}\right]$ erlotinib has been demonstrated only in tumors harboring EGFR exon 19 deletions compared to tumors without activating EGFR mutations [18,19,24,28]. However, the extent to which $\left[{ }^{11} \mathrm{C}\right]$ erlotinib PET could identify NSCLC tumors that harbor other commonly detected TK mutations, such as the activating exon 21 L858R point mutation and the T790M gate-keeper mutation, which confers resistance to TKI therapy, has not been reported.

In the current study, we sought to further explore the potential of $\left[{ }^{11} \mathrm{C}\right]$ erlotinib in differentiating erlotinibsensitive tumors from erlotinib-insensitive or erlotinibresistant ones. To this end, four different human NSCLC cell lines were employed, two of which express the commonly encountered mutations in the EGFR TK domain (delE746-A750 mutation and L858R point mutation) and two additional lines expressing the secondary T790M mutation or wild-type EGFR (wtEGFR). $\left[{ }^{11} \mathrm{C}\right]$ Erlotinib $\mathrm{PET} / \mathrm{CT}$ scans were carried out in athymic nude mice grafted with subcutaneous (s.c.) xenografts of these tumor cell lines. The presented results indicate that $\left[{ }^{11} \mathrm{C}\right]$ erlotinib scans could distinguish NSCLC tumors that express activating mutations in the EGFR TK domain and are sensitive to erlotinib treatment, from tumors that harbor wtEGFR or the double-mutated (L858R + T790M) receptor and do not respond to erlotinib therapy. This data further substantiate the potential of $\left[{ }^{11} \mathrm{C}\right]$ erlotinib PET as a non-invasive tool to identify NSCLC patients who are most likely to benefit from treatment with TKIs and to monitor the mutational status of EGFR during the course of treatment.

\section{Methods}

\section{General}

Insulin, transferrin, HEPES, and sodium pyruvate were purchased from Biological Industries (BI) (Kibbutz Beit Haemek, Israel). Sodium selenite, hydrocortisone, ethanolamine, O-phosphorylethanolamine, 3,3',5-triiodo-Lthyronine $\left(\mathrm{T}_{3}\right)$, and bovine serum albumin (BSA) were purchased from Sigma-Aldrich (Rehovot, Israel). Recombinant human EGF was purchased from PeproTech Asia (Rehovot, Israel).

Hsd:Athymic Nude-Fox1nu mice (male, 4 to 5 weeks) were obtained from Harlan (Rehovot, Israel). All animal studies were conducted under a protocol approved by the Animal Research Ethics Committee of the Hebrew University of Jerusalem and in accordance with its guidelines. Animals were allowed to acclimate for at least 3 
days, prior to their inoculation with tumor cells, and were routinely kept in 12-h light/dark cycles and provided with food and water ad libitum.

\section{Cell culture}

The following human NSCLC cell lines were employed: QG56, HCC827, NCI-H1975, and NCI-H3255. The latter were purchased from the National Cancer Institute - Division of Cancer Treatment and Diagnosis (NCI-DCTD) tumor repository (Frederick, MD, USA) and were regularly maintained in ACL-4 medium, containing insulin (0.02 $\mathrm{mg} / \mathrm{mL})$, transferrin $(0.01 \mathrm{mg} / \mathrm{mL})$, sodium selenite $(25$ $\mathrm{nM})$, hydrocortisone $(50 \mathrm{nM})$, EGF $(1 \mathrm{ng} / \mathrm{mL})$, ethanolamine $(0.01 \mathrm{mM})$, O-phosphorylethanolamine $(0.01 \mathrm{mM})$, triiodothyronine $(100 \mathrm{pM})$, BSA $(0.2 \%(w / v))$, HEPES $(10$ $\mathrm{mM})$, sodium pyruvate $(0.5 \mathrm{mM})$, and L-glutamine $(2 \mathrm{mM})$ in RMPI-1640 medium (Invitrogen ${ }^{\mathrm{Tu}}$, Life Technologies, Carlsbad, MA, USA). HCC827 and NCI-H1975 cells were maintained in RMPI-1640 (\#30-2001, ATCC), and QG56 were grown in RPMI-1640 (Invitrogen ${ }^{\mathrm{Tu}}$ ) at $37^{\circ} \mathrm{C}$ in a humidified atmosphere of $95 \%$ air and $5 \% \mathrm{CO}_{2}$. All media were supplemented with fetal bovine serum (FBS, 10\%) and antibiotics (penicillin $10^{4}$ units/L, streptomycin 10 $\mathrm{mg} / \mathrm{L})$ (BI, Israel).

\section{Inhibition of cell growth}

QG56 (4,000 cells), HCC827, NCI-H3255 (5,000 cells), and NCI-H1975 (7,000 cells) were cultured in 96-well plates. After 24 to $48 \mathrm{~h}$, cells were treated with increasing concentrations (0 to $100 \mu \mathrm{M})$ of erlotinib (Cayman Chemical Company, Ann Arbor, MI, USA). The media containing erlotinib (0.05\% DMSO, $0.1 \%$ ethanol) were freshly prepared and replaced every $24 \mathrm{~h}$. Following $72 \mathrm{~h}$ of treatment, cell growth was determined by methylene blue assay [30]. The median inhibitory concentration $\left(\mathrm{IC}_{50}\right)$ of erlotinib for cell growth of each cell line was calculated using GraphPad Prism 5.0 software. Experiments were repeated thrice for each cell line, in three to six replicates per tested concentration.

\section{NSCLC xenografts}

Mice were anesthetized with isoflurane (1\% to $2 \%$ in oxygen) and injected s.c. in each front flank with a suspension of five million cells in a medium containing Matrigel (BD Biosciences, Beit Haemek, Israel, 20\% (v/v)).

\section{Western blot}

Cell lysates and tumor tissue extracts were prepared in cold $\left(0^{\circ} \mathrm{C}\right.$ to $\left.4^{\circ} \mathrm{C}\right)$ modified RIPA buffer [31], supplemented with protease inhibitor cocktail for mammalian tissues (P8340, Sigma, 1\%). Equal amounts of each sample (30 $\mu \mathrm{g}$ of total protein) were loaded and separated by SDS-PAGE (10\%). Proteins were electrophoretically transferred to a nitrocellulose membrane, and the latter was blocked in 3\% BSA in TBST buffer ( $50 \mathrm{mM}$ Tris- $\mathrm{HCl}$, pH 7.5, $0.1 \%$ Tween 20 , and $150 \mathrm{mM} \mathrm{NaCl}$ ) for $30 \mathrm{~min}$. Corresponding parts of the membrane were incubated overnight $\left(4^{\circ} \mathrm{C}\right.$ with gentle shake) with either of the following primary antibodies, diluted in 3\% BSA/TBST: (1) rabbit polyclonal EGFR 1005 antibody (sc-03, Santa Cruz Biotechnology Inc., Dallas, TX, USA), (2) mouse monoclonal phosphotyrosine PY20 antibody (sc-508, Santa Cruz Biotechnology Inc.), or (3) mouse monoclonal anti- $\beta$ actin antibody (mAbcam 8224, Abcam, Cambridge, UK). The membrane parts were washed thoroughly with TBST buffer and incubated for $1 \mathrm{~h}$ with the corresponding horseradish peroxidase-conjugated IgGs (Santa Cruz Biotechnology Inc.) in $3 \%$ BSA/TBST. Finally, the membranes were washed in TBST, and immunoreactive proteins were visualized using the EZ-ECL kit (BI, Israel). Densitometry was performed using TINA $2.10 \mathrm{~g}$ software, and the intensity of each EGFR band was normalized to that of the corresponding $\beta$-actin band to correct for possible differences in the content of total loaded protein.

\section{$\left[{ }^{11} \mathrm{C}\right]$ Erlotinib synthesis}

The radiosynthesis of $\left[{ }^{11} \mathrm{C}\right]$ erlotinib was based on a previously published procedure $[19,20]$, with slight modifications. $\left[{ }^{11} \mathrm{C}\right] \mathrm{CO}_{2}(50.5 \pm 2 \mathrm{GBq}(n=25))$ was trapped at $-160^{\circ} \mathrm{C}$. Subsequently, the temperature of the cooling trap was increased to $-5^{\circ} \mathrm{C}$, and the activity was transferred by a stream of argon $(40 \mathrm{~mL} / \mathrm{min})$ into the first reactor at $-50^{\circ} \mathrm{C}$, containing $300 \mu \mathrm{L}$ of $0.25 \mathrm{~N}$ lithium aluminum hydride (ABX, Radeberg, Germany) in dry tetrahydrofuran. After $2.5 \mathrm{~min}$, the solvent was removed under reduced pressure, and the reactor temperature was increased to $160^{\circ} \mathrm{C}$. Next, hydroiodic acid $(0.5 \mathrm{~mL}$, Merck, White House Station, NJ, USA) was added, and $\left[{ }^{11} \mathrm{C}\right] \mathrm{CH}_{3} \mathrm{I}$ was distilled through a $\mathrm{NaOH}$ column (Merck) under argon flow $(25 \mathrm{~mL} / \mathrm{min})$ and transferred into a second reactor at $-15^{\circ} \mathrm{C}$, containing $10 \mathrm{mg}$ of 6-O-desmethyl erlotinib (OSI-774, Selleck Chemicals, Houston, TX, USA) dissolved in $0.3 \mathrm{~mL} \mathrm{~N}, N$-dimethylformamide, containing $3.5 \mathrm{mg}$ of sodium hydride. At the end of the 1-min distillation step, $20.6 \pm 1 \mathrm{GBq}(n=25)$ was trapped in the second reactor. The reactor was sealed and heated to $90^{\circ} \mathrm{C}$ for $1.5 \mathrm{~min}$. Then, the reactor temperature was increased to $120^{\circ} \mathrm{C}$ for an additional $5 \mathrm{~min}$. Following a 6.5 -min reaction, volatiles were removed under argon flow (at reduced pressure) at a temperature of $90^{\circ} \mathrm{C}$. The mixture was cooled to $40^{\circ} \mathrm{C}, 0.6 \mathrm{~mL}$ of acetonitrile/water was added, and the crude product was injected into a semipreparative HPLC column, equipped with a variable wavelength UV detector $(254 \mathrm{~nm})$ and a radioactivity detector with NaI crystals. A Phenomenex C18 column $(5 \mu \mathrm{m}, 10$ $\mathrm{mm} \times 250 \mathrm{~mm}$; Torrance, CA, USA) was used, with a mobile phase system of acetonitrile:acetate buffer $0.1 \mathrm{M}, \mathrm{pH}$ 3.8 (4:6), at a constant flow rate of $4 \mathrm{~mL} / \mathrm{min}$. The retention 
time of $\left[{ }^{11} \mathrm{C}\right]$ erlotinib was $10.5 \mathrm{~min}$, and the product was collected into a flask containing $24 \mathrm{~mL}$ HPLC water and $350 \mu \mathrm{L}$ of $1 \mathrm{M} \mathrm{NaOH}$. Subsequently, the solution was passed through a Sep-Pak Plus C18 cartridge (Waters Corporation, Milford, MA, USA), which was pre-activated with $5 \mathrm{~mL} \mathrm{EtOH}$, and washed with $10 \mathrm{~mL}$ HPLC water prior to the synthesis. The cartridge was washed with $4 \mathrm{~mL}$ of water, and $\left[{ }^{11} \mathrm{C}\right]$ erlotinib was eluted using $1.3 \mathrm{~mL}$ of $\mathrm{EtOH}$ followed by $11 \mathrm{~mL}$ of sterile isotonic saline (B. Braun, Melsungen, Germany). Quality control analysis was performed on an analytical HPLC, equipped with a variable wavelength UV detector $(254 \mathrm{~nm})$ and a radioactivity detector with $\mathrm{NaI}$ crystals. A Phenomenex $\mathrm{C} 18$ column $(5 \mu \mathrm{m}, 4.6 \mathrm{~mm} \times 250 \mathrm{~mm}$ ) was used, with a mobile phase system of acetonitrile:acetate buffer $0.1 \mathrm{M}, \mathrm{pH} 3.8$ (37:63) for $30 \mathrm{~min}$, at a constant flow rate of $1 \mathrm{~mL} / \mathrm{min}$.

\section{MicroPET/CT studies}

Tumor-bearing mice $(30 \pm 1 \mathrm{~g}(n=27))$ were anesthetized with isoflurane ( $1 \%$ to $2.5 \%$ in $\mathrm{O}_{2}$ ) and maintained normothermic using a heating pad. Following a CT attenuationcorrection scan, PET acquisitions were carried out in list mode using an Inveon ${ }^{\text {Tw }}$ MM PET-CT small-animal dedicated scanner (Siemens Medical Solutions, Malvern, PA, USA). PET scans were started at the time of $\left[{ }^{11} \mathrm{C}\right]$ erlotinib injection via the lateral tail vein $(16.36 \pm 0.6 \mathrm{MBq}(n=27))$ and lasted for $1 \mathrm{~h}$. Subsequently, mice were maintained at the same position and injected i.v. with $\left[{ }^{18} \mathrm{~F}\right] \mathrm{FDG}(5.67 \pm$ $0.2 \mathrm{MBq}(n=24))$. After a 40-min uptake period, a second 20-min PET acquisition was performed. Carrier-added studies were carried out in HCC827 tumor-bearing mice $(n=5)$, wherein erlotinib $(6.7 \mathrm{mg} / \mathrm{kg}$, dissolved in Cremophor EL/ethanol/saline (1:1:8)) was co-injected with the radiolabeled compound.

Emission sinograms were normalized and corrected for attenuation, scatter, randoms, dead time, and decay. Image reconstruction was performed using Fourier rebinning and two-dimensional ordered-subsets expectation maximization (2D-OSEM), with a voxel size of $0.776 \times$ $0.776 \times 0.796 \mathrm{~mm}^{3}$. Image analysis and quantification were performed using Inveon Research Workplace 4.2 (Siemens Medical Solutions). Delineation of tumors' volumes of interest (VOIs) was performed by manual segmentation, based on the fused $\left[{ }^{18} \mathrm{~F}\right] \mathrm{FDG}$ and $\mathrm{CT}$ images, and the corresponding $\left[{ }^{11} \mathrm{C}\right]$ erlotinib time-activity curves (TACs) were calculated. Distribution of activity was calculated as the percentage of injected dose per milliliter of tissue (\%ID/mL). Standardized uptake values (SUVs) were calculated as the product of $\% \mathrm{ID} / \mathrm{mL}$ and the total body weight of the animal.

\section{Statistics}

Statistical analysis was made using GraphPad Prism 5 software. Unless otherwise stated, data is expressed as mean \pm SEM. Comparisons of $\left[{ }^{11} \mathrm{C}\right]$ erlotinib uptake in tumors in imaging studies were made using one-way ANOVA, followed by the Bonferroni post hoc test. The level of significance was regularly set at $p<0.05$.

\section{Results}

\section{Inhibition of cell growth}

Four human NSCLC cell lines expressing different forms of the EGFR were investigated. Sensitivity of each cell line to the anti-proliferative effect of erlotinib was evaluated by methylene blue assay and is presented in Table 1 . Two cell lines, HCC827 and NCI-H3255, which express activating mutations in the EGFR, were erlotinib-sensitive, having mean $\mathrm{IC}_{50}$ values of 4 and $41 \mathrm{nM}$, respectively. Two additional cell lines, QG56 (expressing wtEGFR) and NCIH1975 (expressing the L858R + T790M point mutations), were significantly less sensitive to erlotinib treatment, with mean $\mathrm{IC}_{50}$ values of 8.9 and $4.3 \mu \mathrm{M}$, respectively. Thus, in vitro, NCI-H3255 and HCC827 cells were 100- to 1,000fold more sensitive to the anti-proliferative effect of erlotinib compared to QG56 and NCI-H1975 cells. In agreement with previous reports, Western blot analysis (Figure 1) indicated that the sensitivity to erlotinib treatment could not be attributed to differences in total EGFR or EGFRassociated phosphotyrosine (PY) levels, since neither of those correlated with erlotinib sensitivity of the tested cell lines $[14,32,33]$.

\section{$\left[{ }^{11} \mathrm{C}\right]$ Erlotinib synthesis}

$\left[{ }^{11} \mathrm{C}\right]$ Erlotinib was obtained after an approximately 40-min synthesis, including formulation, with an average radioactivity of $2.42 \pm 0.3 \mathrm{GBq}(n=25)$ in $12.3 \mathrm{~mL}$ of $10 \% \mathrm{EtOH} /$ saline. The average specific activity at the end of synthesis was $26.14 \pm 2.5 \mathrm{GBq} / \mu \mathrm{mol}(n=25)$, and the radiochemical purity was above $97 \%$.

\section{MicroPET/CT studies}

PET acquisitions of tumor-bearing mice were carried out for $1 \mathrm{~h}$ following i.v. injection of $\left[{ }^{11} \mathrm{C}\right]$ erlotinib. Subsequently, mice were injected with $\left[{ }^{18} \mathrm{~F}\right] \mathrm{FDG}$ and scanned again $40 \mathrm{~min}$ after injection. The $\left[{ }^{18} \mathrm{~F}\right] \mathrm{FDG}$ scans served a

Table 1 Sensitivity of four human NSCLC cell lines to the anti-proliferative effect of erlotinib in vitro

\begin{tabular}{llll}
\hline Cell line & Type of EGFR mutation & $\begin{array}{l}\mathbf{I C}_{50} \text { of } \\
\text { erlotinib }[\boldsymbol{\mu M} \text { ] }\end{array}$ & $\begin{array}{l}\text { Erlotinib } \\
\text { sensitive }\end{array}$ \\
\hline QG56 & None (wtEGFR) & $8.9 \pm 0.5^{* * *}$ & No \\
$\mathrm{HCC} 827$ & Activating (delE746-A750) & $0.004 \pm 0.0009$ & Yes \\
$\mathrm{NCl}$-H3255 & $\begin{array}{l}\text { Activating (L858R point } \\
\text { mutation) }\end{array}$ & $0.041 \pm 0.007$ & Yes \\
$\mathrm{NCl}$-H1975 & $\begin{array}{l}\text { Double mutation (L858R }+ \\
\text { T790M point mutations) }\end{array}$ & $4.3 \pm 0.8^{* * *}$ & No \\
\hline
\end{tabular}

${ }^{* * *} p<0.001$ with respect to $\mathrm{HCC} 827$ cells. 


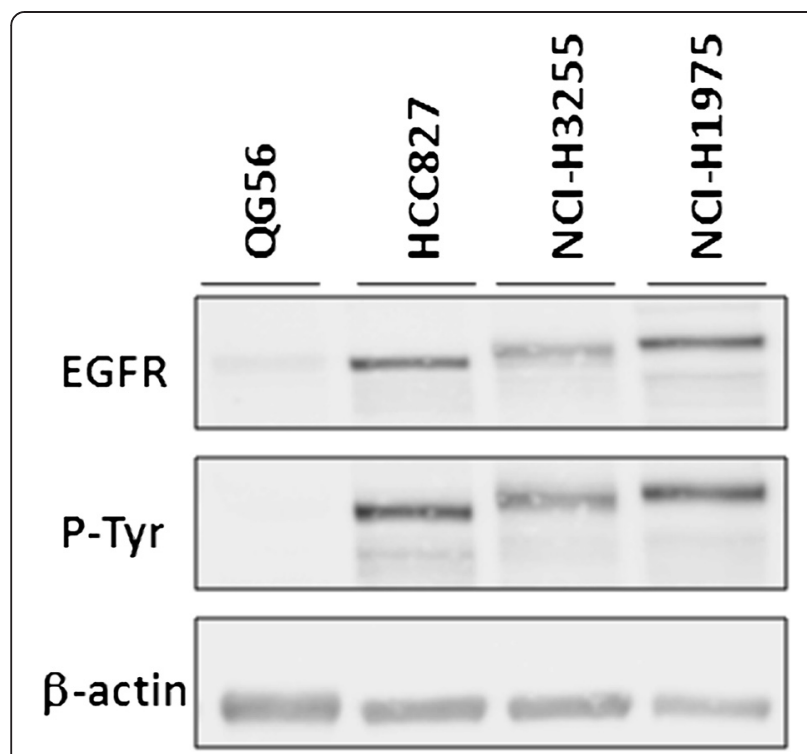

Figure 1 Representative Western blots of four human NSCLC cell lysates comparing the extent of EGFR and phospho-EGFR expression. $\beta$-actin served as a reference for equal loading.

dual purpose: to confirm tumor viability and to delineate the tumor's VOI, particularly in cases where $\left[{ }^{11} \mathrm{C}\right]$ erlotinib uptake in tumor was not prominent (Figure 2).

TACs representing the kinetics in tumors following $\left[{ }^{11} \mathrm{C}\right]$ erlotinib injection are presented in Figure 3, revealing distinct differences between erlotinib-sensitive and erlotinib-insensitive tumors. The uptake in both sensitive tumors, HCC827 and NCI-H3255, was significantly higher than that observed in QG56 and NCI-H1975 tumors, already at $12 \mathrm{~min}$ after injection and throughout the 60-min scan (Figure 3, Table 2). Thus, $\left[{ }^{11} \mathrm{C}\right]$ erlotinib could clearly distinguish erlotinib-sensitive tumors from insensitive ones. Nonetheless, whereas the uptake in HCC827 tumors was high and sustained (SUV $>0.6$ starting 12 min after injection), the peak SUV in NCIH3255 tumors was 0.43 , at the same time point, further declining to 0.33 at $1 \mathrm{~h}$ (Figure 3). In addition, the uptake in HCC827 tumors was specific, as revealed in blocking studies, wherein more than $50 \%$ reduction in tumor uptake was measured after administration of non-labeled erlotinib in excess. Notably, the kinetics of $\left[{ }^{11} \mathrm{C}\right]$ erlotinib in HCC827 tumors in blocking studies was comparable to that measured in NCI-H3255 tumors without the addition of carrier in excess.

\section{Western blot}

The relative expression of total EGFR and EGFR-associated PY levels in the four investigated NSCLC tumors was evaluated by Western blot analysis. The results illustrated in Figure 4 indicated $\mathrm{HCC} 827$ as those expressing the highest levels of EGFR, followed by NCI-H3255 tumors (approximately 73\%), NCI-H1975 (approximately 65\%), and QG56 tumors (approximately 43\%). Moreover, the latter also had significantly lower EGFR-associated PY levels, compared to the other three tumors, wherein similar levels of EGFR-PY were detected.

\section{Discussion}

Target-specific TKIs, peptides, and antibodies have paved the way to a more personalized treatment of cancer, wherein therapy is tailored based on the molecular characteristics of the patients' tumors rather than on tumor staging and histopathology alone [27,34-36]. Nuclear medicine imaging techniques, such as PET and SPECT, offer a highly sensitive and non-invasive means for detecting and quantifying the expression of molecular targets in vivo. Thus, upon development of a suitable radiolabeled pharmaceutical, one could potentially visualize and quantify the expression of specific target proteins in the entire body in a non-invasive, longitudinal manner, instead of relying on site-specific, invasive tissue sampling. This approach could not only simplify patient stratification and selection prior to initiation of targeted therapy, but could also facilitate treatment monitoring and enable prolonged measurement of changes in target expression [37].

Specific EGFR TKIs, such as gefitinib and erlotinib, gained FDA approval for the treatment of advanced NSCLC in 2003 and 2004, respectively. The clinical data gathered thus far indicates that only patients whose tumors harbor distinct activating mutations in the TK domain of the receptor are likely to benefit from first-line treatment with EGFR TKIs. These mutations, typically exon 19 in-frame deletions (approximately 45\%) and the L858R point mutation in exon 21 (40\% to $45 \%$ ), are detected in $10 \%$ to $30 \%$ of NSCLC patients $[38,39]$. The relatively limited prevalence of these sensitizing mutations requires that the EGFR mutational status be verified prior to the initiation of first-line therapy with EGFR TKIs. To date, targeted mutation testing uses specific and sensitive methods, yet it requires tumor biopsy. This approach is invasive and lengthy with regard to the time required for mutation analysis and provides information about the sampled site alone. Moreover, it is not favorable for obtaining molecular information in the long term, as would be required during EGFR TKI therapy, owing to the development of secondary mutations in the receptor and subsequent resistance to TKI treatment $[1,6]$.

The present work further highlights the potential of $\left[{ }^{11} \mathrm{C}\right]$ erlotinib PET in discriminating erlotinib-sensitive NSCLC tumors from erlotinib-insensitive or resistant tumors. This methodology should provide sufficient information vis-à-vis the potential clinical benefit of patients from EGFR TKI therapy, hopefully circumventing the need for invasive tissue biopsies. 

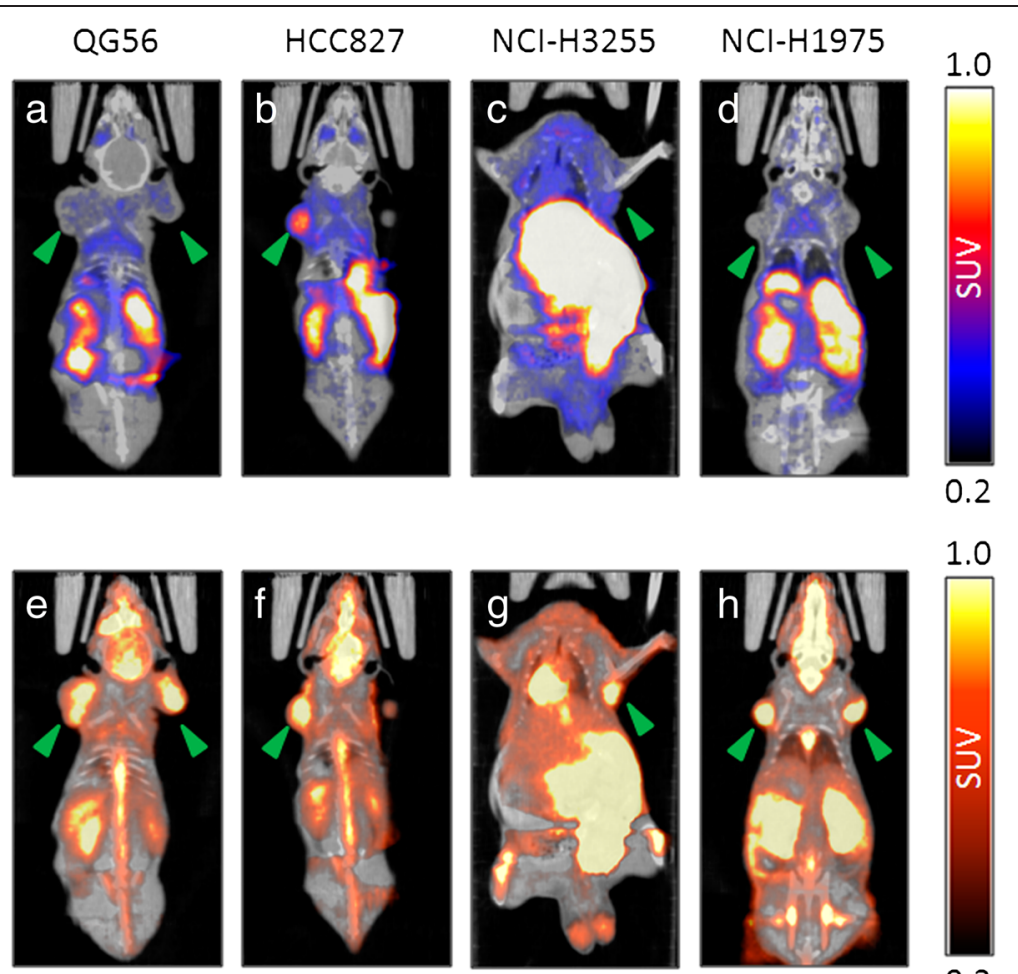

Figure 2 Representative PET/CT slice images of NSCLC tumor-bearing mice. The images were taken following sequential injections of $\left[{ }^{11} \mathrm{C}\right]$ erlotinib (a-d) and $\left[{ }^{18} \mathrm{~F}\right] \mathrm{FDG}(\mathbf{e}-\mathbf{h})$ into each mouse, demonstrating (arrowheads) $\left[{ }^{11} \mathrm{C}\right]$ erlotinib uptake in erlotinib-sensitive tumors (b, $\left.\mathbf{c}\right)$ and in erlotinib-insensitive ones $(\mathbf{a}, \mathbf{d}) \cdot\left[{ }^{11} \mathrm{C}\right]$ Erlotinib and $\left[{ }^{18} \mathrm{~F}\right] \mathrm{FDG}$ images depict the summation of radioactivity uptake from 30 to $60 \mathrm{~min}$ and 40 to 60 min after injection, respectively. Each set of $\left[{ }^{11} \mathrm{C}\right]$ erlotinib and $\left[{ }^{18} \mathrm{~F}\right] \mathrm{FDG}$ images was normalized to the same scale.

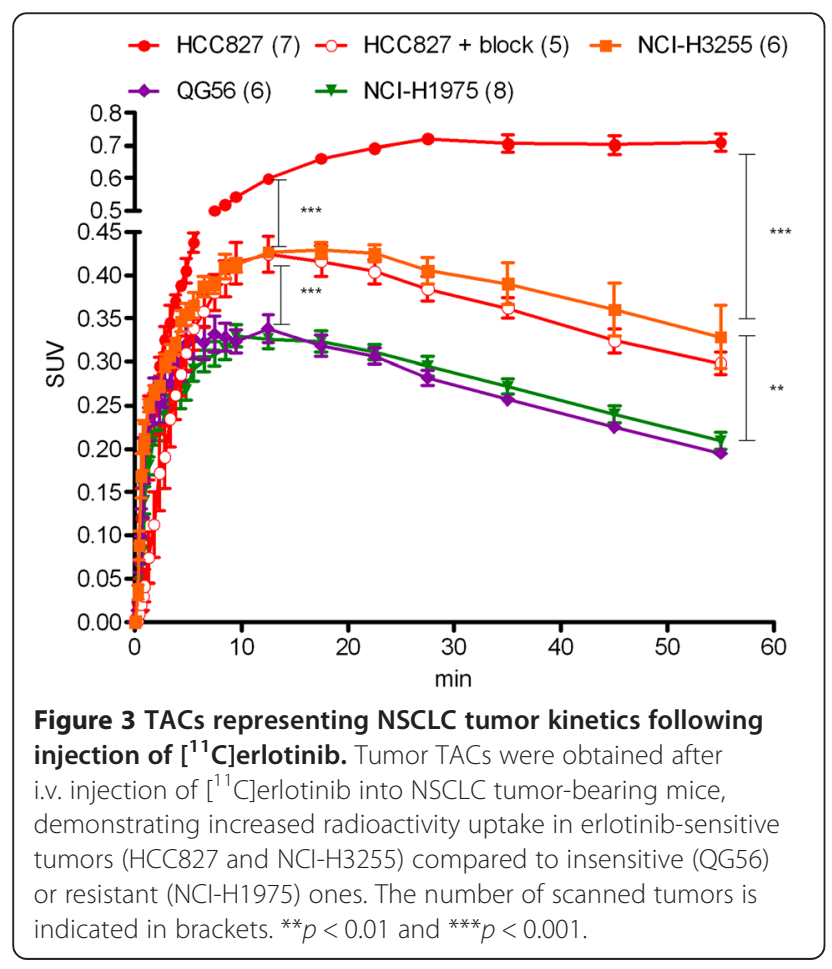

Four human NSCLC tumors were employed in this study, expressing wtEGFR (QG56), the commonly encountered activating mutations in the TK domain of the receptor, namely the delE746-A750 mutation (HCC827) and the L858R point mutation (NCI-H3255) or the L858R+ T790M mutations (NCI-H1975). The latter cell line was selected since secondary mutations in the TK domain, such as the T790M mutation, are encountered in approximately $50 \%$ of EGFR TKI-treated patients, who develop resistance to therapy $[1,6,38]$. The effect of erlotinib on cell proliferation was evaluated in vitro for each cell line, and the

Table 2 Tumor SUVs at early (12 $\mathrm{min})$ and late (60 $\mathrm{min})$ time points after $\left[{ }^{11} \mathrm{C}\right]$ erlotinib injection

\begin{tabular}{lll}
\hline Tumor type & Early SUV & Late SUV \\
\hline QG56 & $0.338 \pm 0.039^{*}(6)$ & $0.195 \pm 0.010^{* * * * * *}(6)$ \\
HCC827 & $0.598 \pm 0.013(4)$ & $0.709 \pm 0.069(7)$ \\
HCC827+ block & $0.424 \pm 0.046^{* *}(5)$ & $0.298 \pm 0.029^{* *}(5)$ \\
NCl-H3255 & $0.427 \pm 0.014^{* *}(6)$ & $0.328 \pm 0.089^{* *}(6)$ \\
NCl-H1975 & $0.326 \pm 0.032^{*}(8)$ & $0.209 \pm 0.028^{* * * * *}(8)$
\end{tabular}

Results are presented as mean $\pm S D$, and the number of scanned tumors is indicated in brackets. ${ }^{*} p<0.001$ with respect to $\mathrm{HCC} 827$ and $\mathrm{NCl}-\mathrm{H} 3255$ tumors. ${ }^{* *} p<0.001$ with respect to $\mathrm{HCC} 827$ tumors. ${ }^{* * *} p<0.01$ with respect to $\mathrm{NCl}-\mathrm{H} 3255$ tumors. 


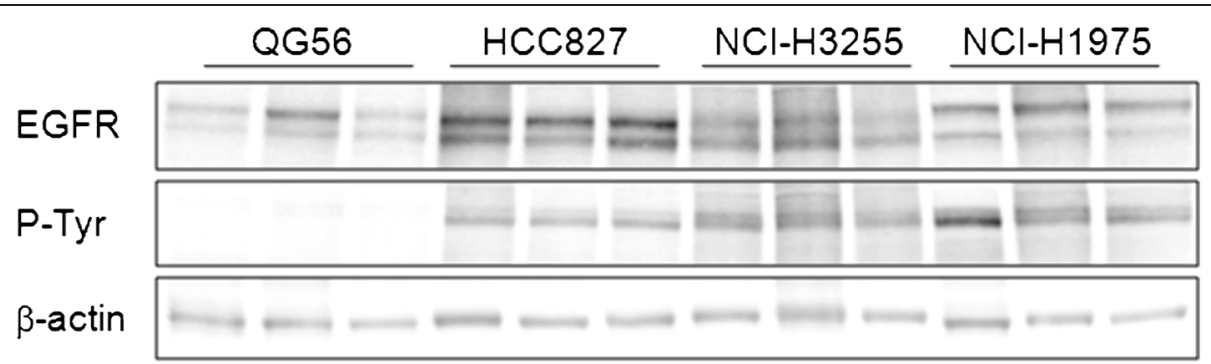

Figure 4 Representative Western blots of NSCLC tumor extracts, demonstrating total EGFR and phospho-EGFR levels in tumors. $n=3$ per group. $\beta$-actin served as a reference for equal loading.

corresponding $\mathrm{IC}_{50}$ values were calculated, as presented in Table 1. The results indicate that HCC827 and NCI-H3255 cells were significantly more sensitive to erlotinib treatment compared to QG56 and NCI-H1975 cells, having mean $\mathrm{IC}_{50}$ values of 4 and $40 \mathrm{nM}$, compared to 8.9 and $4.3 \mu \mathrm{M}$, respectively.

Subsequently, $\left[{ }^{11} \mathrm{C}\right]$ erlotinib PET acquisitions of tumorbearing mice were carried out in order to determine

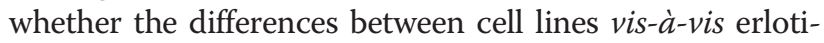
nib sensitivity in vitro could be translated into distinct patterns of $\left[{ }^{11} \mathrm{C}\right]$ erlotinib tumor uptake in vivo. Since $\left[{ }^{11} \mathrm{C}\right]$ erlotinib uptake in tumors was not always evident (Figure 2), an $\left[{ }^{18}\right.$ F]FDG PET acquisition was carried out following each $\left[{ }^{11} \mathrm{C}\right]$ erlotinib scan, as aforementioned. The TACs of $\left[{ }^{11} \mathrm{C}\right]$ erlotinib uptake in tumors are illustrated in Figure 3, revealing statistically significant higher uptake of $\left[{ }^{11} \mathrm{C}\right]$ erlotinib in erlotinib-sensitive tumors vs. erlotinibinsensitive or erlotinib-resistant tumors. This differential uptake was measured as early as $12 \mathrm{~min}$ after $\left[{ }^{11} \mathrm{C}\right]$ erlotinib injection and had lasted throughout the 60-min scan period. Interestingly, however, whereas the profile of $\left[{ }^{11} \mathrm{C}\right]$ erlotinib uptake in both QG56 and NCI-H1975 tumors was almost identical, the uptake of $\left[{ }^{11} \mathrm{C}\right]$ erlotinib in HCC827 tumors was notably different from that observed in NCI-H3255 tumors. Specifically, $\left[{ }^{11} \mathrm{C}\right]$ erlotinib uptake in HCC827 tumors was relatively high and persistent, with mean SUVs of 0.60 and 0.71 at 12 and $60 \mathrm{~min}$, respectively, compared to corresponding mean SUVs of 0.43 and 0.33 for NCI-H3255 tumors (Table 2). Furthermore, the TACs obtained for NCI-H3255 tumors were highly similar to those of HCC827 after co-administration of non-labeled erlotinib in excess.

Several factors could account for the observed differences in both kinetics and absolute $\left[{ }^{11} \mathrm{C}\right]$ erlotinib uptake values in HCC827 vs. NCI-H3255 tumors. First, the overall concentration of the target protein $\left(B_{\max }\right)$ is expected to affect the extent of ligand binding $[24,40]$. Western blot analysis of tumor lysates indicated approximately 30\% lower levels of EGFR in NCI-H3255 tumors compared to HCC827 (Figure 4), consistent with the approximately $30 \%$ lower SUV of $\left[{ }^{11} \mathrm{C}\right]$ erlotinib in NCI-H3255 tumors at $12 \mathrm{~min}$ after injection, the time of peak radioactivity uptake in these tumors (Figure 3). Still, differences in EGFR expression in tumors per se are most likely not the main determinant of the overall observed differences in $\left[{ }^{11} \mathrm{C}\right]$ erlotinib tumor uptake. As was recently demonstrated, elevated expression of EGFR or phospho-EGFR, such as that observed in U87 $\triangle$ EGFR glioma tumors, does not guarantee enhanced uptake of $\left[{ }^{11} \mathrm{C}\right]$ erlotinib [24]. Similarly, our results indicate that although higher levels of EGFR and phospho-EGFR were measured in NCIH1975 compared to QG56 tumors (Figure 4), the uptake of $\left[{ }^{11} \mathrm{C}\right]$ erlotinib in the two xenografts was comparable (Figure 3, Table 2). Thus, the cumulative evidence points to the mutational status of the EGFR TK domain rather than the level of EGFR expression as the major factor affecting $\left[{ }^{11} \mathrm{C}\right]$ erlotinib uptake in tumors. Nonetheless, when comparing the uptake of $\left[{ }^{11} \mathrm{C}\right]$ erlotinib in tumors that harbor activating mutations in the EGFR TK domain, the expression levels of the receptor should come into play [24].

Then, different binding affinities of the EGFR TK mutants to both adenosine triphosphate (ATP) and erlotinib could explain the heterogeneous kinetics of $\left[{ }^{11} \mathrm{C}\right]$ erlotinib in the two erlotinib-sensitive tumors. Carey et al. have demonstrated that compared to wtEGFR, the delE746A750 and L858R mutants had significantly lower binding affinities to ATP, with corresponding approximately 26and approximately 2-fold higher Michaelis-Menten constants $\left(K_{\mathrm{M}}\right)$ with respect to the wtEGFR [41]. At the same time, these mutants were also reported to hold higher affinities to erlotinib, with respective 5.3- and 2.8-fold lower inhibition constant values $\left(K_{\mathrm{i}}\right)$, compared to the wild-type receptor. Consequently, tumors harboring the delE746A750 mutation would be expected to bind $\left[{ }^{11} \mathrm{C}\right]$ erlotinib more avidly than those expressing the L858R mutation.

Increased uptake of $\left[{ }^{11} \mathrm{C}\right]$ erlotinib in tumors harboring the delE746-A750 mutation compared to wtEGFR has been demonstrated in both NSCLC patients [18] and mouse models $[19,24]$. The present results are in good agreement with those published by Petrulli et al. [24], with respect to the sustained uptake of $\left[{ }^{11} \mathrm{C}\right]$ erlotinib in HCC827 tumors, albeit lower mean SUVs were measured in the current study ( 0.7 vs. approximately 1.3 at $60 \mathrm{~min}$ 
after injection). The smaller tumor uptake values measured in this study could partly be attributed to the lower specific activity of $\left[{ }^{11} \mathrm{C}\right]$ erlotinib obtained here $(26.14 \pm 2.5$ $\mathrm{GBq} / \mu \mathrm{mol})$, compared to that published by Petrulli and colleagues (159.1 $\pm 48 \mathrm{MBq} / \mathrm{nmol}$ ) [24], resulting in a higher injected mass of non-labeled carrier. Based on the results of the present research, a proposed correlation between the injected erlotinib mass and the SUV of $\mathrm{HCC} 827$ tumors at $60 \mathrm{~min}$ after injection $\left(\mathrm{SUV}_{60} \mathrm{~min}\right)$ is presented in Figure 5, suggesting that the relationship between the two is exponential rather than linear. Thus, following injection of an 11-fold higher carrier mass $(4.4$ vs. $0.4 \mathrm{nmol})$, the $\mathrm{SUV}_{60}$ min of $\left[{ }^{11} \mathrm{C}\right]$ erlotinib in HCC 827 tumors had decreased by approximately $21 \%$ (from 0.8 to 0.63 ). Consistent with this notion, an excess non-labeled erlotinib dose of approximately $500 \mathrm{nmol}$, such as that administered in this study, should result in an $\mathrm{SUV}_{60}$ min of approximately 0.3 for HCC827 tumors, as was indeed obtained in the blocking experiments (Figure 5). Moreover, if the proposed relation between the injected carrier mass and the $\mathrm{SUV}_{60}$ min of HCC827 tumors is valid, increasing the blocking dose from 6.7 $\mathrm{mg} / \mathrm{kg}$ to approximately $30 \mathrm{mg} / \mathrm{kg}$ should further reduce the $\mathrm{SUV}_{60}$ min of $\mathrm{HCC} 827$ to approximately 0.2 , a value lower than the measured $\mathrm{SUV}_{60}$ min for NCI-H3255 tumors (0.33) and similar to that obtained in QG56 and NCI-H1975 tumors (0.2) (Figure 3, Table 2). This possibility is under investigation.

In the current study, calculation of $\left[{ }^{11} \mathrm{C}\right]$ erlotinib uptake in tumors relied on SUV measurements rather than on kinetic parameters, such as the volume of distribution $\left(V_{\mathrm{T}}\right)$ or the binding potential (BP). Compared to SUV, which does not distinguish target-specific from non-specific binding, $V_{\mathrm{T}}$ and $\mathrm{BP}$ reflect the specific binding and are therefore more sensitive measures of $B_{\max }$.

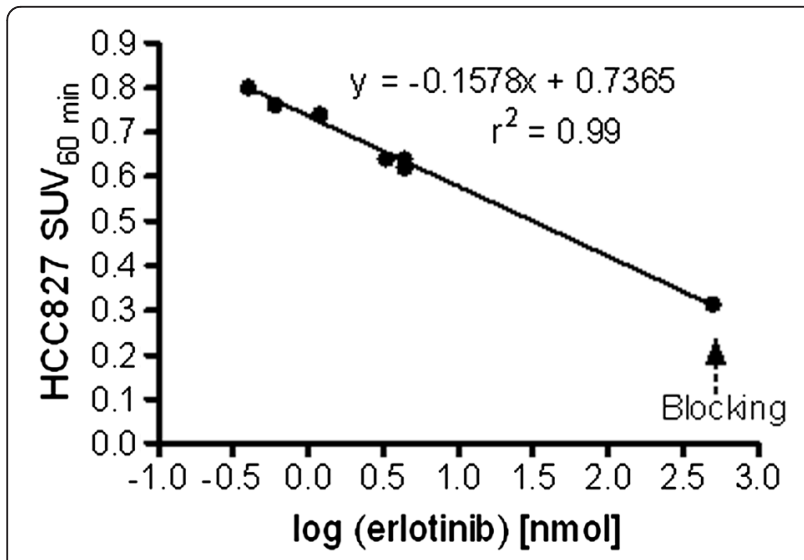

Figure 5 Inverse correlation between $\left[{ }^{11} \mathrm{C}\right]$ erlotinib uptake in HCC827 tumors at 60 min after injection and injected carrier mass. $n=12$. The last point on the right represents the administered blocking dose $(6.7 \mathrm{mg} / \mathrm{kg}, n=5)$.
Nonetheless, the ability to distinguish significant differences in $\left[{ }^{11} \mathrm{C}\right]$ erlotinib uptake between erlotinib-sensitive and erlotinib-resistant tumors using SUVs suggests that a more pronounced difference would have been observed had a kinetic analysis been performed, and provides an initial proof-of-concept prior to the validation by full kinetic analysis.

In addition to $\left[{ }^{11} \mathrm{C}\right]$ erlotinib, the use of $3^{\prime}$-deoxy-3'$\left[{ }^{18} \mathrm{~F}\right]$ fluorothymidine $\left(\left[{ }^{18} \mathrm{~F}\right] \mathrm{FLT}\right)$ PET as a non-invasive tool for identifying TKI-responsive NSCLC tumors has been reported in preclinical mouse models and in humans [42-45]. Commonly, these studies measured the change in $\left[{ }^{18} \mathrm{~F}\right] \mathrm{FLT}$ tumor uptake prior to and after initiation of EGFR TKI therapy, to predict response to treatment. Albeit less straightforward than $\left[{ }^{11} \mathrm{C}\right]$ erlotinib scans, this approach has successfully differentiated TKI-sensitive NSCLC tumors from unresponsive ones. Notably, $\left[{ }^{18} \mathrm{~F}\right] \mathrm{FLT}$ PET scans in NSCLC tumor-bearing mice have demonstrated their utility in identifying TKI-resistant tumors, which harbor the most frequently encountered mutations associated with TKI resistance, i.e., the secondary T790M mutation [44] and MET amplification [43]. In this study, the potential of $\left[{ }^{11} \mathrm{C}\right]$ erlotinib PET in differentiating TKIresistant tumors that contain the T790M mutation from TKI-sensitive tumors has been demonstrated. The utility of this approach to identify TKI-resistant NSCLC tumors with MET amplification warrants further investigation.

\section{Conclusions}

The present study illustrates the usage of $\left[{ }^{11} \mathrm{C}\right]$ erlotinib PET for diagnosing the commonly encountered EGFR TK mutations in NSCLC patients and for discriminating erlotinib-sensitive tumors from erlotinib-insensitive or erlotinib-resistant tumors. To the best of our knowledge, this is the first demonstration of increased $\left[{ }^{11} \mathrm{C}\right]$ erlotinib uptake in NSCLC tumors harboring the L858R point mutation. Overall, these data further corroborate the potential of $\left[{ }^{11} \mathrm{C}\right]$ erlotinib PET in identifying patients who are likely to benefit from EGFR TKI therapy.

\section{Competing interests}

The authors declare that they have no competing interests.

\section{Authors' contributions}

GA participated in the design of the study, acquisition and analysis of PET data, and drafting and revision of the manuscript. BI carried out the in vitro assays, established the tumor models, and participated in the PET acquisitions and data analysis. OS carried out the in vitro assays and participated in the establishment of tumor models. SB carried out the radiosynthesis of $\left[{ }^{11} \mathrm{C}\right]$ erlotinib. EM participated in the design of the study and was involved in the drafting and revision of the manuscript. All authors read and approved the final manuscript.

\section{Acknowledgements}

The authors wish to thank Sassi Cohen, Daniel Wajnblum, Shai Yaacobi, and Sharon Dotan for their technical support and assistance, as well as the National Cancer Institute - the Division of Cancer Treatment and Diagnosis, Frederick, MD, USA, for providing the NCI-H3255 cell line. 
Received: 1 December 2014 Accepted: 19 December 2014 Published online: 12 February 2015

\section{References}

1. Carnio S, Novello S, Mele T, Levra MG, Scagliotti GV. Extending survival of stage IV non-small cell lung cancer. Semin Oncol. 2014;41:69-92.

2. Siegel R, Naishadham D, Jemal A. Cancer statistics, 2013. CA Cancer J Clin. 2013;63:11-30

3. Abourbeh G, Shir A, Mishani E, Ogris M, Rodl W, Wagner E, et al. PolylC GE11 polyplex inhibits EGFR-overexpressing tumors. IUBMB Life. 2012;64:324-30.

4. Chen P, Cameron R, Wang J, Vallis KA, Reilly RM. Antitumor effects and normal tissue toxicity of $111 \mathrm{ln}$-labeled epidermal growth factor administered to athymic mice bearing epidermal growth factor receptor-positive human breast cancer xenografts. J Nucl Med. 2003;44:1469-78.

5. Mamot C, Drummond DC, Greiser U, Hong K, Kirpotin DB, Marks JD, et al. Epidermal growth factor receptor (EGFR)-targeted immunoliposomes mediate specific and efficient drug delivery to EGFR- and EGFRvIlloverexpressing tumor cells. Cancer Res. 2003;63:3154-61.

6. Ratti M, Tomasello G. Emerging combination therapies to overcome resistance in EGFR-driven tumors. Anticancer Drugs. 2014;25:127-39.

7. Lynch TJ, Bell DW, Sordella R, Gurubhagavatula S, Okimoto RA, Brannigan $B W$, et al. Activating mutations in the epidermal growth factor receptor underlying responsiveness of non-small-cell lung cancer to gefitinib. N Engl J Med. 2004;350:2129-39.

8. Paez JG, Janne PA, Lee JC, Tracy S, Greulich H, Gabriel S, et al. EGFR mutations in lung cancer: correlation with clinical response to gefitinib therapy. Science. 2004;304:1497-500.

9. Sordella R, Bell DW, Haber DA, Settleman J. Gefitinib-sensitizing EGFR mutations in lung cancer activate anti-apoptotic pathways. Science. 2004;305:1163-7.

10. Dillon B, Naidoo B, Knight H, Clark P. NICE guidance on erlotinib for first-line treatment of EGFR-TK mutation-positive advanced or metastatic non-small-cell lung cancer. Lancet Oncol. 2012;13:764-5.

11. Rosell R, Carcereny E, Gervais R, Vergnenegre A, Massuti B, Felip E, et al. Erlotinib versus standard chemotherapy as first-line treatment for European patients with advanced EGFR mutation-positive non-small-cell lung cancer (EURTAC): a multicentre, open-label, randomised phase 3 trial. Lancet Oncol. 2012;13:239-46.

12. Riely GJ, Kris MG, Zhao B, Akhurst T, Milton DT, Moore E, et al. Prospective assessment of discontinuation and reinitiation of erlotinib or gefitinib in patients with acquired resistance to erlotinib or gefitinib followed by the addition of everolimus. Clin Cancer Res. 2007;13:5150-5.

13. Yu HA, Arcila ME, Rekhtman N, Sima CS, Zakowski MF, Pao W, et al. Analysis of tumor specimens at the time of acquired resistance to EGFR-TKI therapy in 155 patients with EGFR-mutant lung cancers. Clin Cancer Res. 2013;19:2240-7.

14. Zhao J, Wang X, Xue L, Xu N, Ye X, Zeng H, et al. The use of mutationspecific antibodies in predicting the effect of EGFR-TKIs in patients with non-small-cell lung cancer. J Cancer Res Clin Oncol. 2014;140:849-57.

15. Peled N, Barash O, Tisch U, lonescu R, Broza YY, llouze M, et al. Volatile fingerprints of cancer specific genetic mutations. Nanomedicine. 2013;9:758-66.

16. Yeh HH, Ogawa K, Balatoni J, Mukhapadhyay U, Pal A, Gonzalez-Lepera C, et al. Molecular imaging of active mutant L858R EGF receptor (EGFR) kinase-expressing nonsmall cell lung carcinomas using PET/CT. Proc Natl Acad Sci U S A. 2011;108:1603-8.

17. Abourbeh G, Dissoki S, Jacobson O, Litchi A, Ben Daniel R, Laki D, et al. Evaluation of radiolabeled ML04, a putative irreversible inhibitor of epidermal growth factor receptor, as a bioprobe for PET imaging of EGFR-overexpressing tumors. Nucl Med Biol. 2007;34:55-70.

18. Bahce I, Smit EF, Lubberink M, van der Veldt AA, Yaqub M, Windhorst AD, et al. Development of [(11)C]erlotinib positron emission tomography for in vivo evaluation of EGF receptor mutational status. Clin Cancer Res. 2012:19:183-93.

19. Memon AA, Jakobsen S, Dagnaes-Hansen F, Sorensen BS, Keiding S, Nexo E. Positron emission tomography (PET) imaging with [11C]-labeled erlotinib: a micro-PET study on mice with lung tumor xenografts. Cancer Res. 2009:69:873-8.

20. Memon AA, Weber B, Winterdahl M, Jakobsen S, Meldgaard P, Madsen HH, et al. PET imaging of patients with non-small cell lung cancer employing an EGF receptor targeting drug as tracer. Br J Cancer. 2011;105:1850-5.
21. Meng X, Loo Jr BW, Ma L, Murphy JD, Sun X, Yu J. Molecular imaging with 11C-PD153035 PET/CT predicts survival in non-small cell lung cancer treated with EGFR-TKI: a pilot study. J Nucl Med. 2011;52:1573-9.

22. Mishani E, Hagooly A. Strategies for molecular imaging of epidermal growth factor receptor tyrosine kinase in cancer. J Nucl Med. 2009;50:1199-202.

23. Pal A, Glekas A, Doubrovin M, Balatoni J, Namavari M, Beresten T, et al. Molecular imaging of EGFR kinase activity in tumors with 124l-labeled small molecular tracer and positron emission tomography. Mol Imaging Biol. 2006;8:262-77.

24. Petrulli JR, Sullivan JM, Zheng MQ, Bennett DC, Charest J, Huang Y, et al. Quantitative analysis of [11C]-erlotinib PET demonstrates specific binding for activating mutations of the EGFR kinase domain. Neoplasia. 2013;15:1347-53.

25. Slobbe P, Poot AJ, Windhorst AD, van Dongen GA. PET imaging with small-molecule tyrosine kinase inhibitors: TKI-PET. Drug Discov Today. 2012;17:1175-87.

26. Su H, Seimbille Y, Ferl GZ, Bodenstein C, Fueger B, Kim KJ, et al. Evaluation of [(18)F]gefitinib as a molecular imaging probe for the assessment of the epidermal growth factor receptor status in malignant tumors. Eur J Nucl Med Mol Imaging. 2008;35:1089-99.

27. van Dongen GA, Poot AJ, Vugts DJ. PET imaging with radiolabeled antibodies and tyrosine kinase inhibitors: immuno-PET and TKI-PET. Tumour Biol. 2012;33:607-15.

28. Weber B, Winterdahl M, Memon A, Sorensen BS, Keiding S, Sorensen L, et al. Erlotinib accumulation in brain metastases from non-small cell lung cancer: visualization by positron emission tomography in a patient harboring a mutation in the epidermal growth factor receptor. J Thorac Oncol. 2011:6:1287-9.

29. Zhang MR, Kumata K, Hatori A, Takai N, Toyohara J, Yamasaki T, et al. [11C]Gefitinib ([11 C]lressa): radiosynthesis, in vitro uptake, and in vivo imaging of intact murine fibrosarcoma. Mol Imaging Biol. 2010;12:181-91.

30. Dent MF, Hubbold L, Radford H, Wilson AP. The methylene blue colorimetric microassay for determining cell line response to growth factors. Cytotechnology. 1995;17:27-33

31. Abourbeh G, Theze B, Maroy R, Dubois A, Brulon V, Fontyn Y, et al. Imaging microglial/macrophage activation in spinal cords of experimental autoimmune encephalomyelitis rats by positron emission tomography using the mitochondrial $18 \mathrm{kDa}$ translocator protein radioligand [(1)(8)F]DPA-714. J Neurosci. 2012;32:5728-36.

32. Han SW, Kim TY, Hwang PG, Jeong S, Kim J, Choi IS, et al. Predictive and prognostic impact of epidermal growth factor receptor mutation in non-small-cell lung cancer patients treated with gefitinib. J Clin Oncol. 2005:23:2493-501.

33. Parra HS, Cavina R, Latteri F, Zucali PA, Campagnoli E, Morenghi E, et al. Analysis of epidermal growth factor receptor expression as a predictive factor for response to gefitinib ('rressa', ZD1839) in non-small-cell lung cancer. Br J Cancer. 2004;91:208-12.

34. Conti PS, White C, Pieslor P, Molina A, Aussie J, Foster P. The role of imaging with (111)In-ibritumomab tiuxetan in the ibritumomab tiuxetan (Zevalin) regimen: results from a Zevalin Imaging Registry. J Nucl Med. 2005:46:1812-8.

35. Druker BJ, Guilhot F, O'Brien SG, Gathmann I, Kantarjian H, Gattermann N, et al. Five-year follow-up of patients receiving imatinib for chronic myeloid leukemia. N Engl J Med. 2006;355:2408-17.

36. Teunissen JJ, Kwekkeboom DJ, Valkema R, Krenning EP. Nuclear medicine techniques for the imaging and treatment of neuroendocrine tumours. Endocr Relat Cancer. 2011:18 Suppl 1:S27-51.

37. Velikyan I, Sundin A, Sorensen J, Lubberink M, Sandstrom M, Garske-Roman $U$, et al. Quantitative and qualitative intrapatient comparison of 68Ga-DOTATOC and 68Ga-DOTATATE: net uptake rate for accurate quantification. J Nucl Med. 2014;55:204-10.

38. Cadranel J, Ruppert AM, Beau-Faller M, Wislez M. Therapeutic strategy for advanced EGFR mutant non-small-cell lung carcinoma. Crit Rev Oncol Hematol. 2013;88:477-93.

39. Sharma SV, Bell DW, Settleman J, Haber DA. Epidermal growth factor receptor mutations in lung cancer. Nat Rev Cancer. 2007;7:169-81.

40. Eckelman WC. The application of receptor theory to receptor-binding and enzyme-binding oncologic radiopharmaceuticals. Nucl Med Biol. 1994;21:759-69.

41. Carey KD, Garton AJ, Romero MS, Kahler J, Thomson S, Ross S, et al. Kinetic analysis of epidermal growth factor receptor somatic mutant proteins shows increased sensitivity to the epidermal growth factor receptor tyrosine kinase inhibitor, erlotinib. Cancer Res. 2006;66:8163-71. 
42. Frings V, Yaqub M, Hoyng LL, Golla SS, Windhorst AD, Schuit RC, et al. Assessment of simplified methods to measure 18F-FLT uptake changes in EGFR-mutated non-small cell lung cancer patients undergoing EGFR tyrosine kinase inhibitor treatment. J Nucl Med. 2014:55:1417-23.

43. lommelli F, De Rosa V, Gargiulo S, Panico M, Monti M, Greco A, et al. Monitoring reversal of MET-mediated resistance to EGFR tyrosine kinase inhibitors in non-small cell lung cancer using 3'-deoxy-3'-[18F]-fluorothymidine positron emission tomography. Clin Cancer Res. 2014;20:4806-15.

44. Zannetti A, lommelli F, Speranza A, Salvatore M, Del Vecchio S. 3'-Deoxy-3'18F-fluorothymidine PET/CT to guide therapy with epidermal growth factor receptor antagonists and Bcl-xL inhibitors in non-small cell lung cancer. J Nucl Med. 2012;53:443-50.

45. Sohn HJ, Yang YJ, Ryu JS, Oh SJ, Im KC, Moon DH, et al. [18F]

Fluorothymidine positron emission tomography before and 7 days after gefitinib treatment predicts response in patients with advanced adenocarcinoma of the lung. Clin Cancer Res. 2008;14:7423-9.

Submit your manuscript to a SpringerOpen ${ }^{\odot}$ journal and benefit from:

- Convenient online submission

- Rigorous peer review

- Immediate publication on acceptance

- Open access: articles freely available online

- High visibility within the field

- Retaining the copyright to your article

Submit your next manuscript at $>$ springeropen.com 